\title{
A Pot Technique to Screen Pigeonpea Cultivars for Resistance to Waterlogging
}

\author{
y. S. Chauhan, S. N. Silim, J. V. D. K. Kumar Rao and C. Johansen
}

Authors" address: Dr Y. S. Chauhan, Dr S. N. Silim, Dr J. V. D. K. Kumar Rao and Dr C. Johansen, Internationial Crops Research Institute for the Semi-Arid Tropics (ICRISAT), Asia Center, Patancheru, Andhra Pradesh 502 324. India

With one figure and 3 tables

Received August 16. 1996; accepled November 23. 1996

\section{Abstract}

To develop a preliminary screening procedure for waterlogging resistance, a waterlogging resistant ICP 8379 and a waterlogging susceptible cultivar ICP 7035 were grown in pots using different growth media and subjected to 6 days of waterlogging. Waterlogging caused a significant reduction in root dry mass of both cultivars which was greater in ICP 7035 than in ICP 8379 . The reduction in shoot dry mass was comparatively small. The most conspicuous differences between the two cultivars occurred in terms of plant survival. In different soil treatments, ICP 8379 showed $0-38 \%$ mortality and ICP 7035 showed $63-100 \%$ mortality. The variation in mortality accurred in response to differences in growth medium. Using the growth medium that gave maximum differences, eight additional cultivars were compared along with ICP 7035 and ICP 8379. Significant differences in plant mortality among different cultivars were observed. A number of cultivars showed similar low mortality as ICP 8379. Therefore, there appears to be a potential to use this method for preliminary screening of a large number of pigeonpea cultivars for waterlogging resistance.

Key words: Cajanus cajan L. Millsp., waterlogging resistance

\section{Introduction}

Pigeonpea is an important crop in South Asia, Eastern and Southern Africa, and the Caribbean regions. In some of these regions, rainfall events can be very intensive tesulting in temporary waterlogging or complete flooding of fields. On soils with high water holding capacity, such as Vertisols and Indo-Gangetic Alluvium, short-term waterlogging frequently occurs during the rainy season when pigeonpea is normally grown (Reddy and Virmani, 1981). The risks of crop failure or yield reduction due to short-term waterlogging are particularly acute in extrashort and short-duration genotypes because they have less time to recover from the stress compared to mediumor long-duration cultivars (Matsunaga et al., 1991).

The incidence of short-term waterlogging stress in pigeonpea can be minimized by ensuring good drainage of fields by, for example, ensuring appropriate slopes and preparing the seed bed either into ridges and furrows or broad-bed and furrows (Hodgson et al., 1989; Choudhury and Bhatia, 1971; Kampen, 1982). Application of $\mathrm{N}$ fertilizer to soil during waterlogging stress can also alleviate this stress (Matsunaga et al., 1991). However. these management options are often inadequate as well as expensive. To supplement or substitute these options, the development of cultivars with increased ability to withstand waterlogging stress is necessary. Although not conclusive, there are indications of substantial genotypic differences in waterlogging resistance in pigeonpea (Chauhan, 1987; Dubey and Asthana, 1987). Routine identification of the resistant cultivars has not been possible due to a lack of a reliable screening technique. In the past, some attempts were made to screen pigeonpea in the field (Chauhan. 1987; Dubey and Asthana, 1987). These have. however, met with difficulty due to the inability to control the level of waterlogging and the confounding effects of Phytophthora blight. In addition to predisposing plants to Phytophthora, waterlogging allows infection to spread rapidly from one part of the field to the other (Reddy et al., 1990). These uncertainties have so far discouraged large-scale germplasm screening exercises. These difficulties can perhaps be eliminated in pots using uninfected soil at least for a preliminary screening. This paper reports the results of experiments to explore the feasibility of screening pigeonpea for waterlogging resistance in pots.

\section{Materials and Methods}

The experiments were conducted in the open air $\left(30 / 20^{\circ} \mathrm{C}\right.$ mean maximum/minimum temperatures) at ICRISAT Asia Center. Pigeonpea seeds were sown in round plastic pots of $18 \mathrm{~cm}$ top diameter containing $2 \mathrm{~kg}$ of finely sieved Vertisol (Typic Pellustert) collected from a field where pigeonpea had not been grown for at least 5 years. A basal dose of $28 \mathrm{mg} \mathrm{P} \mathrm{kg-soil}{ }^{-1}$ as single superphosphate was mixed uniformly with the soil in both the experiments to avoid the possibility of $P$ deficiency. The pots had perforations at the bottom and were lined with muslith cloth to allow free drainage of water. In each pot, four uniform seedlings were raised from eight seeds sown 
and kept at about field capacity $(30 \% \mathrm{w} / \mathrm{w})$ until the time of imposing waterlogging stress. A set of replicated ( 3 or 4 times) pots with 40-day-old plants was submerged for up to 8 days in water-filled plastic troughs of $52 \times 22 \times 17$ em dimensions while a similar set of pots containing seedlings was kept in empty troughs as controls. Specific details of each experiment are given below.

\section{Effect of growth medium}

Two cultivars, ICP 7035 which indicated susceptibility and ICP 8379 which indicated resistance to waterlogging in earlier field screening attempts, were sown in pots containing Vertisol on 1 July 1991 in the open air as described above. There were six soil treatments: (a) unsterilized soil without nitrogen (US-N); (b) unsterilized soil with nitrogen (US $+\mathrm{N}$ ); (c) sterilized soil with Rhizobium and without nitrogen ( $\mathrm{SS}+\mathrm{R}-\mathrm{N}$ ); (d) sterilized soil without Rhizobium and with nitrogen ( $\mathrm{SS}-\mathrm{R}+\mathrm{N}$ ); (e) sterilized soil without Rhizobium or nitrogen (SS-R $-\mathrm{N}$ ); and (f) sterilized soil with both Rhizobium and nitrogen $(\mathrm{SS}+\mathrm{R}+\mathrm{N})$. Nitrogen was applied as urea at the rate of $80 \mathrm{mg} \mathrm{pot}^{-1}$ (approximately $80 \mathrm{~kg} \mathrm{ha}^{-1}$ ) in four equal split doses at weekly intervals, starting I week after sowing. Pigeonpea seeds were inoculated with $R h i$ zobium strain IC 3195 as per the treatment at the time of sowing. Plants were subjected to waterlogging at 40 days after sowing for 6 days. Plant survival was recorded 2 days after waterlogging was relieved. Plants were then harvested and dried at $80^{\circ} \mathrm{C}$ for $48 \mathrm{~h}$ to obtain shoot and root dry weights. The experiment was conducted in factorial randomized block design with four replications.

\section{Cultivar differences in waterlogging resistance}

Ten cultivars of medium-duration $(180-200$ days to maturity), JCP 8743, ICP 13562, KPBR 80-2, ICP 8338, ICP 14199, HY 3C, ICP 14114, T 15-15 and ICP 7035 and ICP 8379 were sown in unsterilized soil in the open air on 2 July 1991 . When plants were 40 days old they were waterlogged for 6 days as described above. Plant mortality was recorded 2 days after waterlogging was relieved. The experiments were arranged in factorial randomized block design with three replications and the data on mortality $(\%)$ were recorded and analyzed after angular transformation.

\section{Results and Discussion}

The two criteria that have generally been used in selecting plants for resistance to waterlogging are extent of plant survival and extent of growth reduction (Krizek, 1982). In the present study, we found that plant response in terms of mortality, although representing an extreme response, better distinguished cultivars than the other growth related

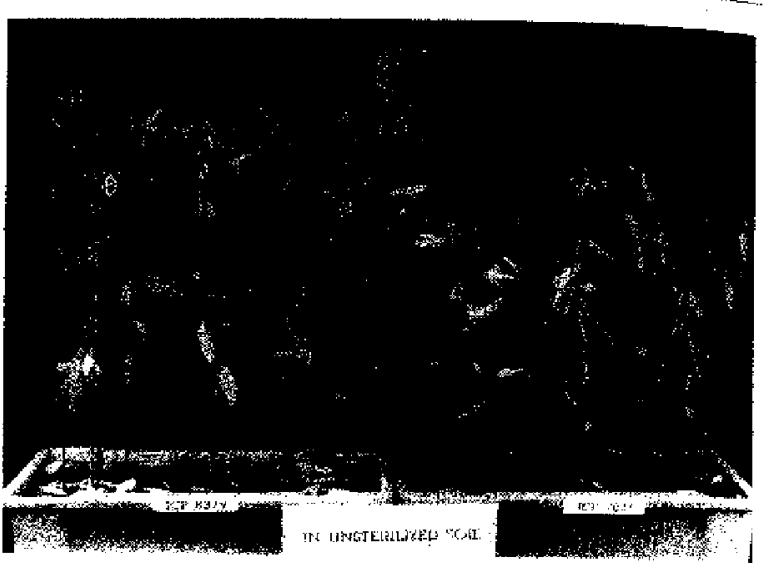

Fig. 1: Effect of 6 days of waterlogging on resistant ( $\mathrm{ICP}$ 8379 , left trough) and susceptible (ICP 7035, right trough cultivars of pigeonpea grown in unsterilized soi]

traits such as root and shoot mass (Table 1, Fig. 1) Moreover, differences that can be assessed visually and efficiently are more appropriate for a rapid screening. Cultivars ICP 7035 and ICP 8379 differed markedly for survival under waterlogging ( $\mathrm{Fig} .1$ ). Significant variation in mortality was observed due to the soil treatments (Table 2). However, the differences in plant mortality between the two cultivars were observed irrespective of the soil treatments. As no mortality occurred in the control trealments, the data for these are not presented. Even though in two of the sterilized soil treatments both cultivars showed comparable mortality as in the unsterilized soil, the development of symptoms was faster in the unsterilized soil (data not shown). The $+\mathrm{N}$ treatments of sterilized soil had lower mortality than the $-\mathrm{N}$ treatments. This is consistent with the results of Matsunaga et al. (1991) who reported that $\mathrm{N}$ application ameliorated the adverse effects of waterlogging. In the present study, a significant beneficial effect of $\mathrm{N}$ application was evident in both resistant and susceptible cultivars in the sterilized soil, but only in the tolerant cultivar in the unsterilized soil. The reasons for this are not clear but could be due to differences in severity of waterlogging stress or susceptibility of the cultivar. Significant differences in mortality between ICP 7035 and ICP 8379 in the unsterilized soil were only observed when they were waterlogged for at least 6 days. In the sterilized soil, development of waterlogging symptoms were slower. This may be due to absence of soil microorganisms which compete for a vailable $\mathrm{O}_{2}$ and also produce phytotoxic substances (Krizek, 1982).

Significant variation in percentage mortality was observed among 10 cultivars including ICP 7035 
Table 1: Effect of waterlogging for 6 days on shoot and root dry mass of two pigeonpea cultivars, ICP 7035 and ICP 8379 , grown in different soil treatments

\begin{tabular}{|c|c|c|c|c|}
\hline \multirow[b]{2}{*}{ Soil treatment $t^{u}$} & \multicolumn{2}{|l|}{ ICP 7035} & \multicolumn{2}{|l|}{ ICP 8379} \\
\hline & Control & Waterlogged & Control & Waterlogged \\
\hline & \multicolumn{4}{|c|}{ Shoot dry weight (g plant') } \\
\hline $\mathrm{US}+\mathrm{R}-\mathrm{N}$ & 2.64 & 1.65 & 2,20 & 1.69 \\
\hline $\mathrm{US}+\mathrm{R}+\mathrm{N}$ & 3.07 & 1.99 & 2.72 & 1.40 \\
\hline$S S+R-N$ & 2.97 & $\therefore \quad 1.02$ & 2.49 & 1.35 \\
\hline$S S-R+N$ & 2.39 & 1.27 & 2.42 & 1.28 \\
\hline$S S-R-N$ & 2.63 & 1.21 & 2.28 & 1.25 \\
\hline $\mathbf{S S}+\mathbf{R}+\mathbf{N}$ & 2.54 & 1.26 & 2.29 & 1.45 \\
\hline \multirow[t]{2}{*}{$\mathrm{SE}$} & \multicolumn{4}{|c|}{ \pm 0.172} \\
\hline & \multicolumn{4}{|c|}{ Root dry weight (g plant ${ }^{-1}$ ) } \\
\hline$U S+R-N$ & 0.70 & 0.22 & 0.60 & 0.31 \\
\hline $\mathrm{US}+\mathrm{R}+\mathrm{N}$ & 0.90 & 0.29 & 0.86 & 0.35 \\
\hline $\mathrm{SS}+\mathrm{R}-\mathrm{N}$ & 1.04 & 0.22 & 0.81 & 0.30 \\
\hline$S S-R+N$ & 0.91 & 0.33 & 0.90 & 0.46 \\
\hline$S S-R-N$ & 0.91 & 0.19 & 0.81 & 0.33 \\
\hline $\mathrm{SS}+\mathrm{R}+\mathrm{N}$ & 1.05 & 0.32 & 0.97 & 0.43 \\
\hline $\mathrm{SE}$ & \multicolumn{4}{|c|}{ \pm 0.086} \\
\hline
\end{tabular}

${ }^{a} \mathrm{US}=$ Unsterilized soil, $\mathrm{SS}=$ Sterilized soil, $\mathrm{R}=$ Rhizobitm, and $\mathrm{N}=$ Nitrogen; + or - denote presence or absence of the factor, respectively, in the treatment.

Table 2: Mortality ( $\%$ ) after 6 days of waterlogging in ICP 7035 and ICP 8379 cultivars grown in different soil treatments

\begin{tabular}{lcc}
\hline Soil treatment & ICP 7035 & ICP 8379 \\
\hline US + R -N & $100(90)^{\mathrm{b}}$ & $38(35)$ \\
US $+\mathrm{R}+\mathrm{N}$ & $100(90)$ & $25(23)$ \\
SS $+\mathrm{R}-\mathrm{N}$ & $100(90)$ & $38(34)$ \\
SS $-\mathrm{R}+\mathrm{N}$ & $75(68)$ & $0(2)$ \\
SS $-\mathrm{R}-\mathrm{N}$ & $100(90)$ & $26(24)$ \\
SS $+\mathrm{R}+\mathrm{N}$ & $63(57)$ & $0(2)$ \\
SE & \multicolumn{2}{c}{$( \pm 3.8)$}
\end{tabular}

${ }^{2} \mathrm{US}=$ Unsterilized soil, $\mathrm{SS}=$ Sterilized soil, $\mathrm{R}=\mathrm{R} h \mathrm{~h}-$ zobium, and $\mathrm{N}=$ Nitrogen; +or - denote presence or absence of the factor, respectively, in the treatment. ${ }^{\mathrm{h}}$ Mean values in parentheses are angular transformed values and SE for comparing them.

and ICP 8379 , which were used as controls. Cultivars ICP 13562 showed lower mortality than the ICP 8379, while ICP 7035 showed $100 \%$ mortality. (Table 3). Cultivars ICP 14199 and KPBR 80-2 were similar to ICP 8379 . These results are in good agreement with field performance of these cultivars (Legumes Program, ICRISAT, 1991). This suggests that
Table 3: Effect of 6 days of waterlogging on percentage mortality in 10 pigeonpea cultivars

\begin{tabular}{lc} 
Cultivar & $\begin{array}{c}\text { Mean mortality } \\
\text { (angular transformed) }\end{array}$ \\
\hline ICP 8743 & $0(1.6)^{\mathrm{a}}$ \\
ICP 13562 & $3(5.8)$ \\
KPBR 80-2 & $14(21.0)$ \\
ICP 8338 & $66(58.0)$ \\
ICP 14199 & $16(23.1)$ \\
HY 3C & $95(82.1)$ \\
ICP 14114 & $70(56.5)$ \\
T-15-15 & $66(61.5)$ \\
ICP 8379 & $11(16.9)$ \\
ICP 7035 & $100(88.4)$ \\
SE & $( \pm 6.88)$
\end{tabular}

${ }^{a}$ Values in parentheses are the angular transformed values and $\mathrm{SE}$ values for comparing them

reproducibility of the method is satisfactory. Reproducibility could be further improved by a better control of soil and aerial environments because these two factors have a large influence on the development of waterlogging symptoms (Thompson and Fick, 1981). However, those cultivars which show 
resistance to waterlogging in variable environmental conditions may be more stitable for diverse waterlogging environments.

For large scale screening of pigeonpea cultivars, it is thus recommended to grow plants of test genotypes in pots as described above together with the susceptible (ICP 7035) and the resistant controls (such as ICP 8379). The plants should ideally be grown in a green house with soil moisture maintained at about $75 \%$ of field capacity to ensure that plants are not waterlogged before treatment imposition. When seedlings are about 40 days old, the pots containing them can be submerged in waterfilled troughs until substantial mortality in the susceptible control occurs coinciding with incipient wilting in the resistant control. Since pigeonpea is a slow growing crop initially, it may not develop enough growth prior to this period (Brakke and Gardner, 1987). A comparison of mortality of the test genotype with the resistant control after relieving waterlogging provides an indication of its resistance. Although ICRISAT maintains a collection of over 12000 pigeonpea germplasm accessions, a selective but systematic approach to germplasm screening is recommended. Initially it is suggested that germplasm accessions derived from waterlogging prone regions and representing major maturity groups should be screened. Genotypes identified resistant at 40 days should also be screened for resistance at later stages. Identification of mechanisms of waterlogging resistance may further help to refine screening procedures for waterlogging resistance in pigeonpea and studies in this regard are in progress.

\section{Zusammenfassung}

\section{Eine Gefaßtechnik zur Auslese von Taubenerbsenkultivaren auf Staunässeresistenz}

Um eine Vorselektion auf Staunässeresistenz zu entwickeln, wurden ein staunässeeresistenter Kultivar ICP 8379 und ein staunässempfindlicher Kultivar ICP 7035 in Gefaßßen unter Verwendung unterschiedlicher Wachstumsmedien und dem Einfluß von 6 Tagen Staunässe angezogen. Staunässebedingungen verursachten eine signikante Reduktion in der Wurzeltrockenmasse beider Kultivare; diese war bei ICP 7035 größer als bej ICP 8379. Die Reduktion in der Sproßtrockenmasse war vergleichsweise gering. Die auffälligsten Unterschiede zwischen den beiden Kuttivaren traten im Himblick auf das Pflanzenüberleben auf. In den unterschiedlichen Bodenbehandlungen starben bei ICP $83790-38 \%$ der Pflanzen ab, während die Absterberate bei ICP $703563-$ $100 \%$ betrug. Die Variation in der Absterberate trat unter Berücksichtigung der Unterschiede in den
Wachstumsmedien auf. Unter Verwendung des Wachstumsmediums mit den stärksten Differenzen wur. den 8 zusätzliche Kultivare im Vergleich mit ICP 7035 und ICP 8379 geprüft. Es wurden signigikante Unterschiede in der Pflanzenabsterberate zwischen den $\mathrm{Ku}$. tivaren beobachtet. Eine Anzahl Kultivare zeigt mit ICP 8379 vergleichbare Absterberaten. Die Vortestmethode scheint daher geeignet, eine Frühausleses für eine grobe Anzahl von Taubernerbsenkultivaren hinsichtlich ihrer Staunässeresistenz vorzunehmen.

\section{Acknowledgements}

We thank the Agronomy Division staff for their assistance in conducting the experiments. Thanks are also due to Genetic Resources Division of ICRISAT for supplying seeds of ICP 14199, ICP 8379, ICP 8743, ICP 13562, ICP 14114 and ICP 8338

\section{References}

Brakke, M. P., and F. P. Gardner, 1987: Juvenile growth in pigeonpea, soybean, and cowpea in relation to seed and seedling characteristics. Crop Science 27, 311--316.

Chauhan, Y. S., 1987: Screening for tolerance to salinity and waterlogging: case studies with pigeonpea and chick pea, In: Adaptation of chickpea and pigeonpea to abiotic stress: proceedings of the consultant's workshop, 19-21 December 1984, ICRISAT Center, India. Patancheru, A. P. India: ICRISAT, pp. 93-103.

Choudbury, S. L., and P. C. Bhatia, 1971: Ridge-planted kharif pulses yield high despite waterlogging. Indian Farm. 21, 8-9.

Dubey, S. D., and A. N. Asthana, 1987: Selection of plant type resistance to waterlogging in pigeonpea. In: E. S. Wallis and D. E. Byth (eds.), Food Legumes Improvement for Asian Farming Systems: Proceedings of an International Workshop, Khon Kaen, Thailand. 1-5 September 1986: ACIAR, p. 311.

Hodgson, A. S., J. F. Holland, and P. Rayner, 1989: Effects of feld slope and duration of furrow irrigation on growth and yield of six grain legumes on a waterlogging prone Vertisol. Field Crops Res. 22, 165180 .

Kampen, J. 1982. An approach to improved productivity on deep Vertisols. Information Bulletin No, 11. Patancheru, A.P. India: ICRISAT, $14 \mathrm{pp}$.

Krizek, P. T., 1982: Plant responses to atmospheric stress caused by waterlogging. In: Christiansen, $M$. N. and C. F. Lewis (eds.), Breeding plants for less favourable environments, Wiley, New York, USA: pp. 293-334.

Legumes Program, ICRISAT (International Crops Research Institute for the Semi-Arid Tropics), 1991: Annual Report 1990. Patancheru, Andhra Pradesh 502324, India: the program, pp. $33 \cdots 34$.

Matsunaga, R., O. Ito, S. Tobita, and T. P. Rao, 1991: Response of the pigeonpea (Cajanus cajan (L.) Millsp.) to nitrogen application and temporary waterlogging, In: L. Kutschera, E. Hübl, E. Lichtenegger, H. Persson, 
and M. Sobotic (eds.), Root ecology and its practical application, pp. 183-1863. IR R Symp. Wien Uni. Bodenkultur, Klagenfurt.

Reddy, M. V., S. B. Sharma, and Y. L. Nene, 1990. Pigeonpea: disease management. In: Y. L. Nene, V. K. Sheila and S. D. Hall (eds.), The Pigeonpea, CAB International, Wallingford, Oxon, UK and ICRISAT, Patencheru Andhra Pradesh, India, pp. 303-347.
Reddy, S. J., and S. M. Virmani, 198:1: Pigeonpea and its climatic environment. In: Proceedings of the International Workshop on Pigeonpea, Vol. 1. 15-19 December 1980, ICRISAT Center India, A.P India, [CRISAT, pp. 259-270.

Thompson, T. E. and G. W. Fick, 1981: Growth response of alfalfa to duration of soil flooding and to temperature, Agron. J. 73, 329-332. 
This document is a scanned copy of a printed document. No warranty is given about the accuracy of the copy. Users should refer to the original published version of the material. 